\title{
The optical, physical and chemical properties of the products of glyoxal uptake on ammonium sulfate seed aerosols
}

\author{
M. Trainic ${ }^{1}$, A. Abo Riziq ${ }^{1}$, A. Lavi ${ }^{1}$, J. M. Flores ${ }^{2,3}$, and Y. Rudich ${ }^{1}$ \\ ${ }^{1}$ Department of Environmental Sciences, Weizmann Institute, Rehovot 76100, Israel \\ ${ }^{2}$ Department of Particle Chemistry, Max Planck Institute for Chemistry, Mainz 55128, Germany \\ ${ }^{3}$ University of Mainz, Institute for Atmospheric Physics, Mainz 55099, Germany
}

Received: 28 June 2011 - Published in Atmos. Chem. Phys. Discuss.: 5 July 2011

Revised: 6 September 2011 - Accepted: 11 September 2011 - Published: 20 September 2011

\begin{abstract}
The heterogeneous reaction between gas phase glyoxal and ammonium sulfate (AS) aerosols, a proxy for inorganic atmospheric aerosol, was studied in terms of the dependence of the optical, physical and chemical properties of the product aerosols on initial particle size and ambient relative humidity (RH). Our experiments imitate an atmospheric scenario of a dry particle hydration at ambient RH conditions in the presence of glyoxal gas followed by efflorescence due to decrease of the ambient RH. The reactions were studied under different $\mathrm{RH}$ conditions, starting from dry conditions $(\sim 20 \% \mathrm{RH})$ and up to $90 \% \mathrm{RH}$, covering conditions prevalent in many atmospheric environments, and followed by consequent drying of the reacted particles before their analysis by the aerosol mass spectrometer (AMS), cavity ring down (CRD) and scanning mobility particle sizer (SMPS) systems. At $\lambda=355 \mathrm{~nm}$, the reacted aerosols demonstrate a substantial growth in optical extinction cross section, as well as in mobility diameter under a broad range of $\mathrm{RH}$ values (35-90\%). The ratio of the product aerosol to seed aerosol geometric cross section reached up to $\sim 3.5$, and the optical extinction cross-section up to $\sim 250$. The reactions show a trend of increasing physical and optical growth with decreasing seed aerosol size, from $100 \mathrm{~nm}$ to $300 \mathrm{~nm}$, as well as with decreasing RH values from $90 \%$ to $\sim 40 \%$. Optically inactive aerosols, at the limit of the Mie range $(100 \mathrm{~nm}$ diameter) become optically active as they grow due to the reaction. AMS analyses of the reaction of $300 \mathrm{~nm}$ AS at RH values of $50 \%, 75 \%$ and $90 \%$ show that the main products of the reaction are glyoxal oligomers, formed by acetal formation in the presence of AS. In addition, imida-
\end{abstract}

Correspondence to: Y. Rudich (yinon.rudich@weizmann.ac.il) zole formation, which is a minor channel, is observed for all reactions, yielding a product which absorbs at $\lambda=290 \mathrm{~nm}$, with possible implications on the radiative properties of the product aerosols. The ratio of absorbing substances (C-N compounds, including imidazoles) increases with increasing RH value. A core/shell model used for the investigation of the optical properties of the reaction products of AS with gas phase glyoxal, shows that the refractive index (RI) of the reaction products are $n=1.68( \pm 0.10)+0.01( \pm 0.02)$ at $50 \% \mathrm{RH}$ and $n=1.65( \pm 0.06)+0.02( \pm 0.01)$ at $75 \% \mathrm{RH}$ at $355 \mathrm{~nm}$. The observed increase in the ratio of the absorbing substances is not indicated in the imaginary part of the products at $\mathrm{RH} 50 \%$ and $75 \%$. A further increase in the ratio of absorbing substances and a resulting increase in the imaginary part of the RI at higher RH values is expected, and may become even more substantial after longer reaction times, possibly in cloud or fog droplets. This study shows that the reaction of abundant substances present in atmospheric aerosols, such as AS, and gas phase glyoxal alters the aerosols' optical, physical and chemical properties and may have implications on the radiative effect of these aerosols.

\section{Introduction}

Aging of aerosol particles in the atmosphere is an important process, leading to products with new chemical and physical properties, higher molecular weight (MW), higher oxidation state, and therefore hygroscopicity, as well as altered optical properties. Therefore, investigating the effect of atmospheric condensed-phase reactions is vital for better understanding and modeling of aerosols' atmospheric role in climate and health. Aging occurs via oxidation reactions by abundant

Published by Copernicus Publications on behalf of the European Geosciences Union. 
radicals such as $\mathrm{OH}, \mathrm{O}_{3}, \mathrm{NO}_{3}$ and $\mathrm{Cl}$ (Rudich, 2003; Rudich et al., 2007), as well as by reactive organic gases, such as glyoxal (Hallquist et al., 2009; Heald et al., 2008; Jimenez et al., 2009; Volkamer et al., 2007; Zhang et al., 2007), and may contribute to the formation of secondary organic aerosols (SOA).

SOA constitute an important fraction of tropospheric aerosol mass (Jimenez et al., 2009). They form via oxidation of VOCs and their consequent condensation onto aerosols, but also include products of condensed-phase chemical processes. An important path for SOA production is through cloud processing and reactions in aqueous phase aerosol (Carlton et al., 2007; Ervens et al., 2011; Hallquist et al., 2009; Kroll and Seinfeld, 2008; Tan et al., 2009). SOA may contain oligomers and other high MW species, such as $\mathrm{Hu}-$ mic Like Substances (HULIS) (Graber and Rudich, 2006; Kalberer et al., 2004). SOA physical, chemical and optical properties are a major source of uncertainty in aerosol sciences. Their formation is probably underestimated in current models, despite their large contribution to aerosol mass (Ervens et al., 2011; Hallquist et al., 2009; Kanakidou et al., 2005).

Ammonium sulfate (AS) is a ubiquitous component of global anthropogenic aerosols, particularly in the accumulation mode, which renders it a highly efficient scatterer in the actinic light range. It scatters in both the visible and the near UV wavelengths, and is a hygroscopic aerosol component with a deliquescence point at approximately $80 \%$ relative humidity $(\mathrm{RH})$, while the dehydration process involves hysteresis, with an efflorescence point at $\sim 35 \% \mathrm{RH}$ (Cruz and Pandis, 2000; Cziczo and Abbatt, 1999; Dinar et al., 2007).

Glyoxal is produced mainly from the photooxidation of biogenic and anthropogenic volatile organic compounds (VOCs) by $\mathrm{OH}$ radical-initiated oxidation of anthropogenic aromatic VOCs, alkenes and acetylene, reactions of $\mathrm{O}_{3}$ with alkenes, and by the oxidation of biogenic molecules such as isoprene (Fu et al., 2008; Myriokefalitakis et al., 2008; Volkamer et al., 2007, 2009). Its typical atmospheric concentrations range from 0.01-5 ppb (Grosjean et al., 1996; Grossmann et al., 2003; Liggio et al., 2005b; Volkamer et al., 2007; Wittrock et al., 2006). Glyoxal is found in urban environments, such as mega-cities, over the oceans and in forests, including tropical rain forests, and in biomass burning regions, it is also found in marine and coastal sites, and rural locations (Fu et al., 2008, 2009; Huisman et al., 2011; Myriokefalitakis et al., 2008; Sinreich et al., 2007; Volkamer et al., 2007). Due to their high solubility and reactivity in the aqueous phase, glyoxal and other $\alpha$-dicarbonyls contribute substantially to SOA formation, mainly via cloud processing, while the photolysis of glyoxal significantly contributes to $\mathrm{HO}_{\mathrm{x}}\left(\mathrm{OH}+\mathrm{HO}_{2}\right)$ chemistry in the gas phase (Carlton et al., 2007; Ervens et al., 2008; Fu et al., 2008; Hallquist et al., 2009). Glyoxal participates in reactive uptake when liquid water is present, and is therefore scavenged by hydrated aerosol, or fog and cloud droplets (Corrigan et al., 2008;
Hastings et al., 2005; Kroll et al., 2005; Liggio et al., 2005b; Schweitzer et al., 1998).

Several studies have investigated the processes by which glyoxal is introduced into aerosol and facilitates SOA formation (Carlton et al., 2007; Corrigan et al., 2008; De Haan et al., 2009; Galloway et al., 2009; Hastings et al., 2005; Kroll et al., 2005; Liggio et al., 2005a; Noziere et al., 2009; Schwier et al., 2010; Shapiro et al., 2009). The reactive uptake of glyoxal by ammonium ion-containing aerosol has been shown to be an important pathway for gas phase glyoxal depletion and can account for the observed excess of glyoxal in liquid phase aerosol compared to those expected based on its Henry's law values. The products of the reaction between inorganic salts, including AS, and glyoxal, as well as other carbonyl compounds, are mostly oligomeric species, formed by a reaction in which the salt acts as a catalyst for the oligomerization of carbonyl compounds by acetal formation (in the case of glyoxal) or by aldol condensation (Corrigan et al., 2008; Galloway et al., 2009; Kroll et al., 2005; Liggio et al., 2005b; Noziere et al., 2009, 2010). Noziere et al. (2009) have conducted a series of reactions between AS and glyoxal in the bulk phase, and have identified two main peaks in the UV-Vis absorption spectrum; a peak at $\lambda=209 \mathrm{~nm}$, and a smaller peak at $\lambda=290 \mathrm{~nm}$. The first peak is attributed to the formation of glyoxal oligomers, produced via two suggested mechanisms, either oligomerization by acetal formation or nucleophilic attack of the glyoxal by the ammonium ion followed by water loss. The latter can also form heterocyclic products with C-N bonds, which can account for the observed peak at $\lambda=290 \mathrm{~nm}$. According to Galloway et al. (2009) the oligomers absorb in the short UV (peak at 200nm and less), which corresponds well with the UV-Vis spectrum peak at $\lambda=209 \mathrm{~nm}$ observed by Noziere et al. (2009), and are therefore optically irrelevant to the troposphere. In addition, Galloway et al. (2009) found that glyoxal oligomerization in the aqueous phase is reversible and concentration-dependent. The reaction of AS with glyoxal also produces imidazoles (the second mechanism suggested by Noziere et al., 2009), which absorb UV radiation at $\lambda=290 \mathrm{~nm}$, and as a result may influence atmospheric absorption at an important range of the actinic flux, where photolysis leads to $\mathrm{OH}$ formation (Cho, 2004; Galloway et al., 2009; Hewitt and Harrison, 1985; Noziere et al., 2009; Schulze, 1973; Sjostedt et al., 2007). Therefore, aerosol absorption at this wavelength can have significant implications on radiative transfer and atmospheric chemistry.

The heterogeneous reaction between AS seed aerosols and gas phase glyoxal was also studied in terms of the chemical and physical properties of the product aerosols, as well as the kinetics and thermodynamics of the reaction (Galloway et al., 2009; Kroll et al., 2005; Liggio et al., 2005a, b; Shapiro et al., 2009). Galloway et al. (2009) and Kroll et al. (2005) performed their studies in the Caltech $28 \mathrm{~m}^{3}$ Teflon environmental chambers, using hydrated polydisperse aerosol populations under varying glyoxal gas phase concentrations and $\mathrm{RH}$ 
values. Under dark conditions, both studies have established the formation of oligomeric species of glyoxal and Galloway et al. (2009) have also observed the formation of C-N compounds, among which are imidazoles. Liggio et al. (2005a, b) used various hydration states of a monodisperse aerosol population and found similar chemical products. All studies show growth in size and mass under various hydration levels, and no growth under dry conditions, confirming that the mechanism of uptake and subsequent oligomerization of gas phase glyoxal on AS seed aerosols requires hydrated conditions. Galloway et al. (2009) demonstrate that the reaction of glyoxal with ammonia is induced by the deprotonation of the ammonium ion in the AS particle by a water molecule, and leads to imidazole formation (Galloway et al., 2009).

In this paper we study the changes in the optical properties of AS aerosols due to the heterogeneous reaction with gas phase glyoxal. We establish, for the first time, the dependence of the optical, chemical and physical properties of the reaction products on the initial particle size and on the $\mathrm{RH}$ conditions. The RH values chosen in this study are atmospherically relevant, ranging from low ambient $\mathrm{RH}$ values, found in arid regions up to values of $90 \%$, typical for tropical regions or in close vicinity of clouds. By following the change in optical, physical and chemical properties of a specific initial AS particle size while varying the RH values, we determine the effect of RH on the reaction. In the same manner, we inter-compare the effect of size on the reaction while keeping the RH constant. In addition, we determine the effect of the heterogeneous reaction on the optical properties of the aerosol particles using cavity ring down aerosol spectrometer (CRD-AS).

\section{Methodology}

\subsection{Aerosol generation and classification}

A schematic of the laboratory setup used is shown in Fig. 1. Aerosols were generated by the method described in detail in our previous publications (Dinar et al., 2008; Lang-Yona etal., 2009; Abo Riziq et al., 2007). Briefly, an aqueous solution of AS $(0.04 \mathrm{M}-0.11 \mathrm{M})$ is nebulized with dry nitrogen flow; the formed droplets are dried by passing through two silica gel diffusion dryer columns, and consequently charged by a neutralizer (TSI model 3012A). Size selection of the resulting dry polydisperse aerosol population is achieved with an electrostatic classifier (differential mobility analyzer (DMA), TSI model 3081), after which the nearly monodisperse aerosol flow is directed into a humidification stage consisting of a nafion humidifier with a temperature controlled bath. This setup allows control of the aerosol flow RH by varying the bath temperature. The hydrated aerosol flow enters a 301 reaction vessel into which gas phase glyoxal is introduced. The residence time in the reactor is approximately $1 \mathrm{~h}$, after which the aerosol population is dried by two additional silica gel diffusion dryer columns. The $\mathrm{RH}$ at the exit of the dryers was measured to be $5 \%( \pm 3 \%)$. After drying the particles are introduced into a scanning mobility particle sizer (SMPS, TSI model 3080) for determination of size distribution and concentration of the dried reacted particles. An $80 \mathrm{~cm}^{3} \mathrm{~min}^{-1}$ flow is directed into the Aerodyne High Resolution Time of Flight Aerosol Mass Spectrometer (HR-ToF-AMS , Aerodyne) system for determination of the chemical properties, and $800 \mathrm{~cm}^{3} \mathrm{~min}^{-1}$ are introduced into a pulsed cavity ring down (CRD) system for determination of their optical properties (see Fig. 1).

In each experiment, we set an initial dry AS particle size and conducted the reaction with gas phase glyoxal in the $\sim 1 \mathrm{~h}$ residence time reaction vessel, under various $\mathrm{RH}$ values (Fig. 1). For the measurement of the optical properties we used the CRD-AS system at $\lambda=355 \mathrm{~nm}$. By choosing this wavelength we were hoping to observe the increase in absorption due to the formation of imidazoles. Although their peak absorption is at $\lambda=290 \mathrm{~nm}$, there is a tail of absorption extending to $\lambda=355 \mathrm{~nm}$ as well. Due to increased absorption by the mirrors, shorter wavelengths could not be studied. The wavelength at $\lambda=355 \mathrm{~nm}$ is atmospherically important because it is within the actinic light reaching the earth's atmosphere and the absorption by organic substances is enhanced as we move from the visible towards the UV part of the spectrum. For each RH value, we measured prior, during and after the reaction, the extinction coefficient $\left(\alpha_{\text {ext }}\right)$ of the dry particles using the CRD-AS system at $\lambda=355 \mathrm{~nm}$ and calculated the extinction cross section $\left(\sigma_{\text {ext }}\right)$ from Eqs. (12 ), while simultaneously measuring the dry mean diameter of the particles with the SMPS.

\subsection{CRD-AS system}

The CRD-AS system was described in details elsewhere (Dinar et al., 2008; Lang-Yona et al., 2009; Abo Riziq et al., 2007 , 2008). Briefly, a pulsed laser light of $\sim 1 \mathrm{~mJ}$ at $\lambda=$ $355 \mathrm{~nm}$ is injected into a cavity containing two highly reflective mirrors (reflectivity, $R=99.9$ ) where it undergoes multiple passes. The light intensity decays exponentially with a characteristic time constant which is a function of the mirror reflectivity and the losses within the cavity. When scatterers and/or absorbers are introduced into the cavity, the light decays faster and the extinction coefficient can be established (Eq. 1).

$\alpha_{\mathrm{ext}}=\frac{L}{d c}\left[\frac{1}{\tau}-\frac{1}{\tau_{0}}\right]$

where $\alpha_{\text {ext }}$ is the measured extinction coefficient, $\tau_{0}$ is the characteristic decay time for aerosol-free cavity, $\tau$ is the cavity ring-down time in the presence of particles, $L / d$ is the ratio of the total cavity length to the cavity length occupied by particles, and $c$ is the speed of light. Using the particle number concentration, the extinction cross section $\left(\sigma_{\mathrm{ext}}\right)$ at a 


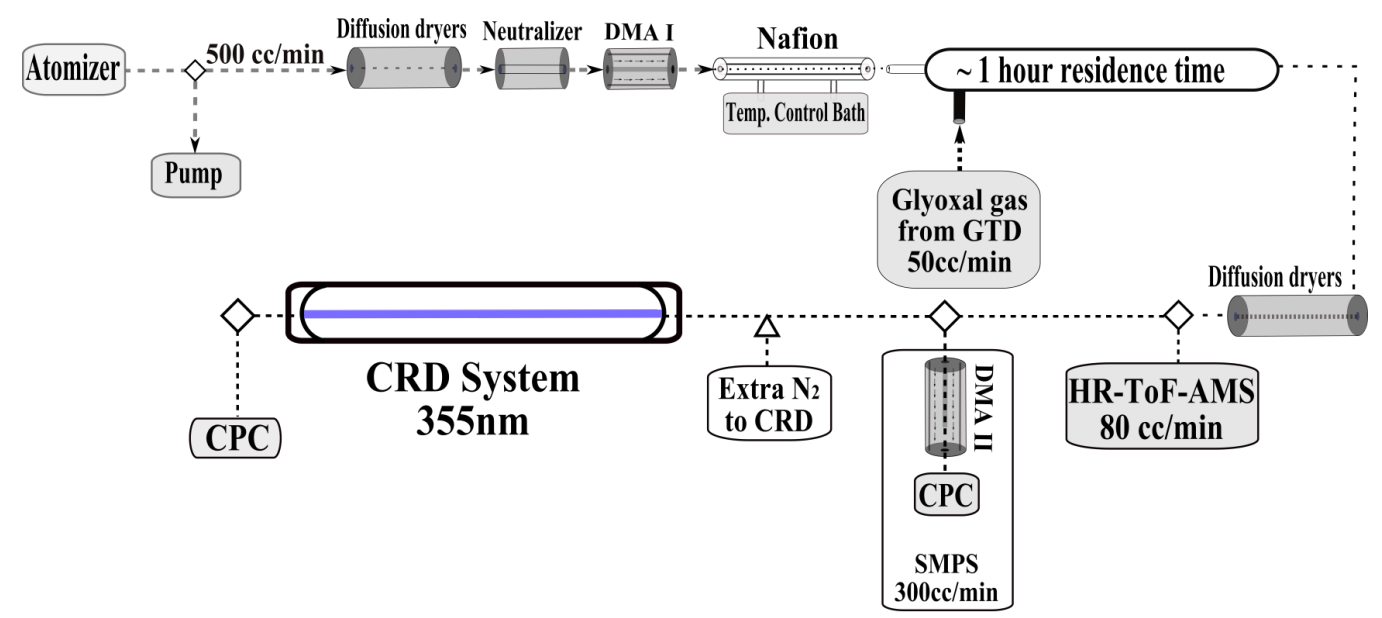

Fig. 1. The experimental setup for the heterogeneous reaction experiments of AS particles with glyoxal.

Acronyms:

DMA - Differential Mobility Analyzer,

AMS - Aerosol Mass Spectrometer,

CPC - Condensation Particle Counter,

SMPS - Scanning Mobility Particle Sizer,

CRD - Cavity Ring Down (spectrometer),

Hepa - High efficiency particulate air.

specific wavelength can be calculated (Eq. 2) (Lang-Yona et al., 2009; Pettersson, 2004; Abo Riziq et al., 2007, 2008).

$\sigma_{\mathrm{ext}}=\frac{\alpha_{\mathrm{ext}}}{N}$

Where $N$ is the particle number concentration, determined by a condensation particle counter (CPC, TSI model 3022A). For spherical particles, the extinction efficiency $\left(Q_{\text {ext }}\right)$ can be calculated using Eq. (3).

$Q_{\text {ext }}=4 \frac{\sigma_{\text {ext }}}{\pi D^{2}}$

where $D$ is the particle mean diameter. By fitting the curve of $Q_{\text {ext }}$ versus the size parameter $\chi$ (the ratio of the particle circumference $(\pi D)$ to the laser's wavelength $(\lambda)$, given by $\chi=\pi D / \lambda)$ to a Mie theory calculation, the complex refractive index (RI) can be retrieved by varying independently the real and the imaginary parts of the RI.

\subsection{Glyoxal gas generation and concentration measurement}

Gas phase glyoxal was added to the reaction vessel by flowing $50 \mathrm{~cm}^{3} \mathrm{~min}^{-1}$ of pure dry $\mathrm{N}_{2}$ through a bulb containing solid phase glyoxal trimer dihydrate (GTD) (97\%, Sigma Aldrich) heated to $110^{\circ} \mathrm{C}$, based on the method used by Harries and Temme (1907), Corrigan et al. (2008) and Galloway et al. (2009).
The concentration of the glyoxal gas was measured with the CRD-AS system at a wavelength of $\lambda=405 \mathrm{~nm}$, using equation 4 for measurement of gaseous species.

conc $=\frac{\alpha_{\mathrm{abs}}}{\sigma_{\mathrm{abs}}}$

where $\alpha_{\text {abs }}$ is the absorption coefficient measured by the CRD-AS system $\left[\mathrm{cm}^{-1}\right), \sigma_{\mathrm{abs}}$ is the absorption crosssection $\left[\mathrm{cm}^{2}\right.$ molecule $\left.{ }^{-1}\right]$, and conc is the gas concentration [molecule $\mathrm{cm}^{-3}$ ]. The value of $\sigma_{\text {abs }}$ at $\lambda=405 \mathrm{~nm}$ is $4.491 \times 10^{-20} \mathrm{~cm}^{2}$ molecule ${ }^{-1}$ (Volkamer et al., 2005). This measurement yields a glyoxal concentration in the reaction vessel of $1.6 \pm 0.5 \mathrm{ppb}$.

\section{Results and discussion}

Following $1 \mathrm{~h}$ of mixing between a selected size of AS aerosol and gas phase glyoxal, the resulting aerosol size distribution, optical and chemical properties were measured with an SMPS, a CRD-AS system and an AMS, respectively. The reaction time is within the timescale previously observed for the heterogeneous reaction between AS particles and gas phase glyoxal (Galloway et al., 2009; Kroll et al., 2005; Liggio et al., 2005a, b).

\subsection{Optical and physical properties}

In this section we establish the dependence of the optical and physical properties of the dry product aerosols on initial particle size and on the RH (and hence, hydration state of the 
Table 1. The final sizes and optical cross sections compared to the initial values, for AS particles with mean diameters of $101 \mathrm{~nm}$, $201 \mathrm{~nm}$, $252 \mathrm{~nm}$ and $304 \mathrm{~nm}$, measured by the SMPS, and the growth ratios of the geometric and optical cross sections for all measured RH values.

\begin{tabular}{lllllll}
\hline $\begin{array}{l}\text { Initial } \\
\text { size }(\mathrm{nm})\end{array}$ & $\begin{array}{l}\text { \% RH } \\
( \pm 3 \%)\end{array}$ & $\begin{array}{l}\text { Final } \\
\text { size }(\mathrm{nm})\end{array}$ & $\begin{array}{l}\text { Ratio of final } \\
\text { to initial geometric } \\
\text { cross section growth }\end{array}$ & $\begin{array}{l}\text { Initial } \\
\sigma_{\text {ext }}\left(\mathrm{cm}^{2}\right)\end{array}$ & $\begin{array}{l}\text { Final } \\
\sigma_{\text {ext }}\left(\mathrm{cm}^{2}\right) \text { growth }\end{array}$ \\
\hline \multirow{3}{*}{$101 \pm 6$} & 50 & $186 \pm 26$ & $3.38 \pm 0.03$ & & $\begin{array}{l}\sigma_{\text {ext }} \\
\text { ratio }\end{array}$ \\
& 75 & $156 \pm 20$ & $2.40 \pm 0.02$ & $2.34 \times 10^{-12} \pm 9.76 \times 10^{-10} \pm 1.02 \times 10^{-12}$ & $2.79 \times 10^{-10} \pm 9.37 \times 10^{-13}$ & 119 \\
& 90 & $136 \pm 10$ & $1.81 \pm 0.01$ & & $1.39 \times 10^{-10} \pm 8.27 \times 10^{-13}$ & 59 \\
\hline & 50 & $357 \pm 39$ & $3.15 \pm 0.03$ & & $3.71 \times 10^{-9} \pm 1.99 \times 10^{-12}$ & 9 \\
$201 \pm 15$ & 75 & $312 \pm 33$ & $2.42 \pm 0.02$ & $4.09 \times 10^{-10} \pm 1.00 \times 10^{-12}$ & $2.67 \times 10^{-9} \pm 2.16 \times 10^{-12}$ & 7 \\
& 91 & $272 \pm 26$ & $1.83 \pm 0.01$ & & $1.65 \times 10^{-9} \pm 1.90 \times 10^{-12}$ & 4 \\
\hline & 19 & $248 \pm 18$ & $0.97 \pm 0.01$ & & $1.25 \times 10^{-9} \pm 3.60 \times 10^{-12}$ & 1 \\
& 30 & $246 \pm 20$ & $0.95 \pm 0.01$ & & $4.31 \times 10^{-9} \pm 4.89 \times 10^{-12}$ & 4 \\
& 35 & $363 \pm 50$ & $2.07 \pm 0.02$ & $1.13 \times 10^{-9} \pm 5.46 \times 10^{-11}$ & $6.83 \times 10^{-9} \pm 6.23 \times 10^{-12}$ & 6 \\
$252 \pm 19$ & 40 & $422 \pm 42$ & $2.80 \pm 0.02$ & & $5.57 \times 10^{-9} \pm 6.65 \times 10^{-12}$ & 5 \\
& 50 & $398 \pm 45$ & $2.50 \pm 0.02$ & & $4.72 \times 10^{-9} \pm 5.55 \times 10^{-12}$ & 4 \\
& 75 & $366 \pm 38$ & $2.10 \pm 0.02$ & & $2.99 \times 10^{-9} \pm 3.39 \times 10^{-12}$ & 3 \\
& 91 & $290 \pm 29$ & $1.32 \pm 0.01$ & & $6.64 \times 10^{-9} \pm 9.82 \times 10^{-12}$ & 3 \\
$304 \pm 22$ & 75 & $378 \pm 43$ & $1.55 \pm 0.01$ & $2.06 \times 10^{-9} \pm 1.85 \times 10^{-11}$ & $5.09 \times 10^{-9} \pm 1.68 \times 10^{-11}$ & 2 \\
& 91 & $339 \pm 33$ & $1.24 \pm 0.01$ & & $4.37 \times 10^{-9} \pm 7.97 \times 10^{-12}$ & 2 \\
\hline
\end{tabular}

aerosol) for the reaction between AS particles and gas phase glyoxal.

Figure 2a shows the final optical extinction cross-sections $\left(\sigma_{\text {ext }}\right)$, and Fig. $2 \mathrm{~b}$ the final mean diameters $(\mathrm{nm})$ for the dry aerosol products of the reaction of $250 \mathrm{~nm}$ AS particles with gas phase glyoxal under varying $\mathrm{RH}$ values. The RH range is from $20 \%$ (dry aerosol) up to $90 \%$. Up until a threshold of $35 \% \mathrm{RH}$, the reaction does not occur at all, there is no change in optical properties and size. At the RH value of $35 \%$, a reaction is observed. Table 1 show that the maximum change occurs at $40 \% \mathrm{RH}$, where the dry mean diameter of the particles measured by the SMPS grows in $\sim 1 \mathrm{~h}$ from $250 \mathrm{~nm}$ to $420 \mathrm{~nm}$, and $\sigma_{\text {ext }}$ reaches $6.83 \times 10^{-9} \mathrm{~cm}^{2}$, a 6 fold increase from the initial value of $\sigma_{\text {ext }}$ of $1.13 \times 10^{-9} \mathrm{~cm}^{2}$ for AS aerosol. The magnitude of change decreases in both size and $\sigma_{\text {ext }}$ with increasing RH value from $40 \%$ to $90 \%$, however it remains significant at all RH values up to $90 \%$, where the size increases to $290 \mathrm{~nm}$ and $\sigma_{\text {ext }}$ reaches $2.99 \times 10^{-9} \mathrm{~cm}^{2}$ (values and their corresponding error are given in Table 1). Therefore, at all RH values in which the reaction occurs, i.e. $35 \%-90 \%$, the reaction leads to more optically active aerosols. The final mean diameters $(\mathrm{nm})$ and $\sigma_{\text {ext }}$ of the products of the $\sim 1 \mathrm{~h}$ heterogeneous reactions of AS $100 \mathrm{~nm}$, $200 \mathrm{~nm}$ and $300 \mathrm{~nm}$ particles with glyoxal gas at RH values varying from $50 \%$ to $90 \%$ have also been studied, and exhibit the same trend as the AS $250 \mathrm{~nm}$ (Table 1). As expected, no reaction occurs in dry AS particles, since the reaction requires hydrated conditions (Galloway et al., 2009;

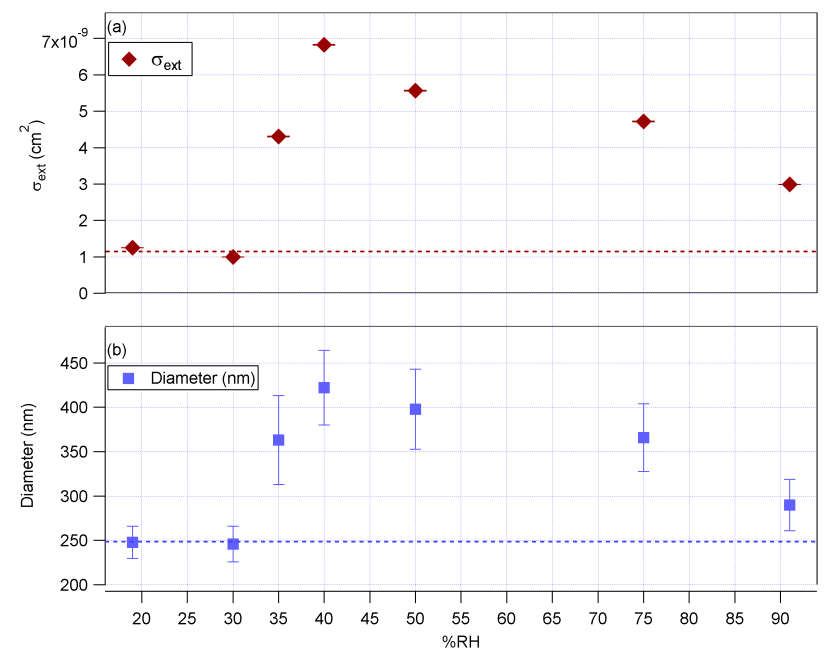

Fig. 2. The results of the $\sim 1 \mathrm{~h}$ heterogeneous reaction of AS $250 \mathrm{~nm}$ particles with gas phase glyoxal at $\mathrm{RH}$ values varying from $20 \%$ to $90 \%$ (while hydrating). (a) The extinction cross sections, $\sigma_{\text {ext }}$ $\left(\mathrm{cm}^{2}\right)$ (red diamonds). (b) The final mean diameters $(\mathrm{nm})$ (blue cubes).

Kroll et al., 2005; Liggio et al., 2005a, b). The hygroscopic growth of AS has been extensively studied (Cruz and Pandis, 2000; Cziczo and Abbatt, 1999; Dinar et al., 2007; Gysel et al., 2002). Its deliquescence RH (DRH) was found at 
$\sim 80 \%$ with hysteresis upon dehydration, leading to an efflorescence point at $\sim 35 \%$ RH. Galloway et al. (2009), Kroll et al. (2005), and Liggio et al. (2005a, b) also show that a reaction occurs at low relative humidities of RH $50 \%$ and less. Mikhailov et al. (2009) (Fig. 5b in their paper) showed that approximately 2 water monolayers are formed on the surface of AS particle at low RH values. The authors suggest that from approximately $\sim 20 \% \mathrm{RH}$ up to $45 \% \mathrm{RH}$ there might be adsorption of water monolayers or restructuring at the surface of the AS particles, and from $45 \% \mathrm{RH}$ their measurements are more robust and are attributed to water adsorption only. Their conclusions are consistent with earlier measurements and estimations (Galloway et al., 2009; Kroll et al., 2005; Liggio et al., 2005a, b). Therefore, we suggest that the reaction we observe under low RH conditions may proceed through water adsorption onto the AS particles by forming a thin aqueous layer on the particle. Our findings that there is no reaction at low RH values of $20-35 \% \mathrm{RH}$ are in agreement with the assumption of Mikhailov et al. (2009) that any observed changes in particle size at these $\mathrm{RH}$ values are attributed to restructuring rather than water uptake. However, while their findings show certain water uptake only at $45 \%$ $\mathrm{RH}$, our results indicate that water uptake occurs already at $35 \% \mathrm{RH}$, when a reaction is observed.

The water monolayers enable partial dissolution of the glyoxal gas and of a small amount of AS at the outer layer of the particle, leading to a highly concentrated component around the particle. Mikhailov et al. (2009) observed an increase from $\sim 2$ monolayers at $50 \% \mathrm{RH}$ to $\sim 6$ monlayers at $75 \%$ $\mathrm{RH}$ and deliquescence after $\sim 80 \% \mathrm{RH}$. This may also explain why the change in the optical and physical cross sections of the product aerosol is smaller with increasing $\mathrm{RH}$ values from $50 \%$ to $90 \%$, since at this $\mathrm{RH}$ range increasing RH values yield higher water content in the outer layer of the AS particles, which in turn leads to a less concentrated aqueous component in the outer layer of the particle, where the reaction takes place, and by that decreasing the reaction rate. This phenomenon is elaborately explored in the next section (see Sect. 3.2).

Figure 3 shows the comparison of the growth ratios of the optical extinction cross-sections, for all measured AS sizes. Figure 3 and Table 1 demonstrate the dependence of the growth in physical and optical cross sections on the initial AS particle size. The growth in the optical and physical cross sections of the product aerosol is enhanced with decreasing initial AS particle size. Additionally, the optical extinction growth ratios exceed the geometric growth (Table 1). This is especially evident in the case of AS $100 \mathrm{~nm}$ particles. In this case, while the growth in geometric cross section due to the reaction is in the same order as for all other AS particle sizes, ranging from 1.81 for RH $90 \%$ to 3.28 for RH $50 \%$ (Table 1), the optical cross sections increase by two orders of magnitude in all measured $\mathrm{RH}$ values. At $50 \% \mathrm{RH}, \sigma_{\mathrm{ext}}$ increases 244 times from $2.34 \times 10^{-12}$ of AS $100 \mathrm{~nm}$ particle to $5.71 \times 10^{-10} \mathrm{~cm}^{2}$ after the reaction, at $75 \% \mathrm{RH}$ it

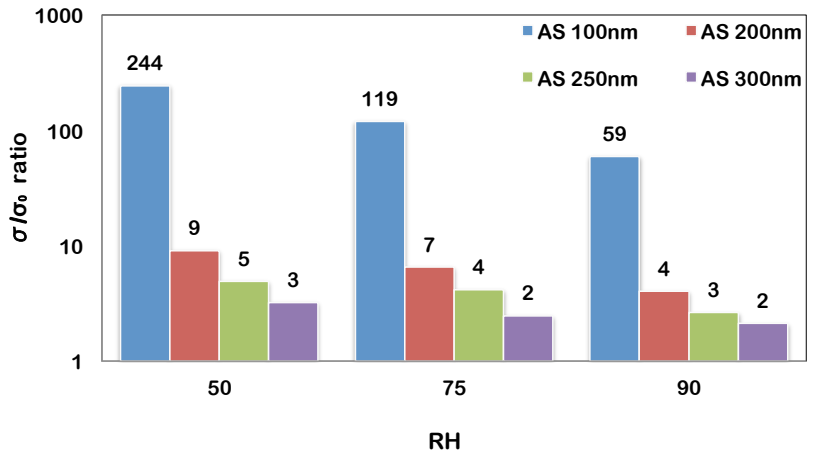

Fig. 3. The ratio of the extinction cross section after reaction $(\sigma$; $\mathrm{cm}^{2}$ ) to the initial extinction cross section $\left(\sigma_{0}\right)$ of the dry AS particles with initial sizes of $100 \mathrm{~nm}$ (blue), $200 \mathrm{~nm}$ (red), $250 \mathrm{~nm}$ (green), and $300 \mathrm{~nm}$ (purple) after a $\sim 1 \mathrm{~h}$ heterogeneous reaction with glyoxal gas at $\mathrm{RH}$ values varying from $50 \%$ to $90 \%$.

increases 119 fold to $2.79 \times 10^{-10}$ and at $90 \%$ RH 59 times reaching $\sigma_{\text {ext }}$ of $1.39 \times 10^{-10}$. This substantial increase in optical cross section is mostly due to the fact that $100 \mathrm{~nm}$ particles at a wavelength of $\lambda=355 \mathrm{~nm}$ have a size parameter of 0.88 , yielding near-zero $Q_{\text {ext }}$ values due to the shape of the Mie curve. When the particles grow to larger sizes due to the reactive uptake of glyoxal, the resulting size parameter is at the steepest increase of the Mie curve and therefore leads to a very substantial increase in $Q_{\text {ext }}$ and consequently in $\sigma_{\text {ext }}$ values. Therefore, the effect of this reaction can be significant since under most atmospheric conditions it can alter a major fraction of the aerosol population from having negligible radiative effect into optically active aerosols. Furthermore, as expected from Fig. 2, the reaction, followed by optical and physical growth, occurs already at $35 \% \mathrm{RH}$ and is most significant at $40 \% \mathrm{RH}$, which has great implications on the radiative properties of the reacted aerosol under these environmental conditions.

To investigate the optical properties of the chemical products due to the heterogeneous uptake of glyoxal by AS aerosol, we calculated the $Q_{\text {ext }}$ of the product particles using Eq. (3). All reacted aerosols have $Q_{\text {ext }}$ values that are different from the values of pure AS. We implemented the obtained $Q_{\text {ext }}$ values in a core/shell model to obtain the RI of the reaction products which is assumed to be in a reacted shell over an unreacted core of ammonium sulfate (modified from the code of Liu et al., 2007). The core/shell model assumes that the structure of the product aerosol is that of an AS core and the shell in this model is assumed to be the added material from the substances formed by the reaction. The model was used to investigate the reaction of gas phase glyoxal with AS seed aerosols at $50 \%$, and $75 \%$ RH. It could not be used for $90 \%$ RH because this value is above the AS particles' deliquescence point and hence a core + shell structure of the final product particles is not applicable, but rather complete 
Table 2. The average shell RIs for the reacted particles of the AS at two RH values, retrieved from the core/shell model.

\begin{tabular}{lcc}
\hline & $\begin{array}{c}\text { Average RI calculated using } \\
\text { the core/shell model for AS } \\
250 \mathrm{~nm} \text { and } 300 \mathrm{~nm} \text { particles }\end{array}$ \\
\cline { 2 - 3 } $\mathrm{RH}$ & Real part & Imaginary part \\
\hline $50 \%$ & $1.68 \pm 0.10$ & $0.01 \pm 0.02$ \\
$75 \%$ & $1.65 \pm 0.06$ & $0.02 \pm 0.01$ \\
\hline
\end{tabular}

mixing of the AS and the reaction products is expected. Since there is no deliquescence at $50 \%$ and $75 \% \mathrm{RH}$, we assume a small layer of water around the AS seed, and therefore can say that the change in core diameter due to dissolution is negligible. The RI retrieval of a mixed particle with a single known $Q_{\text {ext }}$ value can result in a very wide range of RIs. The input for the core/shell model is the AS RI, the total $Q_{\text {ext }}$ of the particle, the particle total size, and the sizes of the core and shell, presented as the mean diameters obtained by the SMPS. The model is based on Mie theory and therefore assumes spherical particles. It retrieves the RI of the shell by first varying the possible RI values of the shell and calculating the corresponding $Q_{\text {ext }}$ and then finding the minimum square deviation between the measured and the modeled $Q_{\text {ext }}$ values. The core size of the particles is the AS initial diameter, with an RI of $n=1.553 \pm 0.005+i 0.002 \pm 0.013$. Table 2 shows the results of the model calculations for the average RI of the shells of AS $250 \mathrm{~nm}$ and $300 \mathrm{~nm}$ particles at two $\mathrm{RH}$ values. The obtained RI value at $355 \mathrm{~nm}$ at $50 \% \mathrm{RH}$ is $n=1.68( \pm 0.10)+0.01( \pm 0.02)$ and at $75 \%$ the retrieved RI is $n=1.65( \pm 0.06)+0.02( \pm 0.01)$. We expect the output RI values to have large uncertainties associated with the limited data provided to the model. Nonetheless, this model provides a first estimation of the RI of the reaction products at $\lambda=355 \mathrm{~nm}$. This may significantly contribute to the scarcely available information of optical properties of organic SOA from such reactions.

\subsection{AMS analysis results}

The changes in chemical composition were monitored with the high-resolution time of flight aerosol mass spectrometer (HR-ToF-AMS AMS). Figure 4 shows the ratio of the mass of the main glyoxal oligomer fragments, of fragments of $\mathrm{C}-\mathrm{N}$ compounds and of imidazole $(\mathrm{m} / \mathrm{z}, 68)$ to sulfate mass, before the reaction of AS $300 \mathrm{~nm}$ with gaseous phase glyoxal, and after the reaction at RH values of $50 \%, 75 \%$ and $90 \%$. The mass peaks considered in the AMS analysis are taken from the studies of Galloway et al. (2009) and Liggio et al. (2005a, b). The fragments of glyoxal oligomerization products are composed of $\mathrm{m} / \mathrm{z}, 29,30,47,58,60,77,88,105,117,135$, 145, 175, 192 and 193. The C-N compounds are the sum

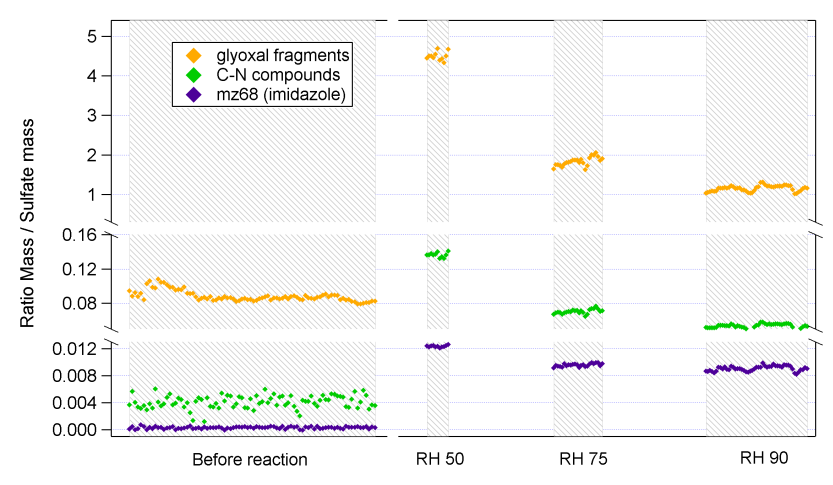

Fig. 4. The total glyoxal fragments (orange diamonds), total C-N compounds (green diamonds) and $\mathrm{m} / \mathrm{z} 68$ (imidazole) (purple diamonds) normalized to sulfate $\left(\mathrm{SO}_{4}\right)$ mass for the reaction of AS $300 \mathrm{~nm}$ particles with glyoxal are presented for 4 periods: (a) before the reaction (pure AS particles), (b) after $\sim 1 \mathrm{~h}$ reaction at $\mathrm{RH}$ $50 \%$, (c) after $\sim 1 \mathrm{~h}$ reaction at $\mathrm{RH} 75 \%$, and (d) after $\sim 1 \mathrm{~h}$ reaction at RH $90 \%$.

of $\mathrm{m} / \mathrm{z} 41,46,52,53,57,68,69,70$ and 96 . We use $\mathrm{m} / \mathrm{z}$ 68 for the imidazole peak from the analysis of Galloway et al. (2009). All masses are normalized to sulfate mass to account for losses during the reaction, according to the method used by Galloway et al. (2009) and by Liggio et al. (2005a, b). The glyoxal oligomerization products increase after the reaction onset by two orders of magnitude compared to the background values present before the reaction, and decrease with increasing $\mathrm{RH}$, in accordance with the observed trend in geometric cross section and $\sigma_{\text {ext }}$ shown in Figs. 2-3 and in Table 1. This trend can be attributed to an increase in the dilution of the AS aerosol with increasing RH. As suggested by Liggio et al. (2005b), the dilution in higher RH values slows the oligomerization process. Noziere et al. (2009) have shown that the $\mathrm{NH}_{4}^{+}$ion acts as a catalyst for the reaction of glyoxal oligomerization by acetal formation, and hence the dilution of the AS due to higher water content in the particle is likely to decrease the reaction rate.

The glyoxal oligomerization products are the main products of this reaction, with total mass/sulfate mass ratios of $4.5 \pm 0.1$ after the reaction at RH $50 \%, 1.8 \pm 0.1$ at RH $75 \%$, and $1.2 \pm 0.1$ for RH $90 \%$. The normalized mass values of C-N compounds are between 1-2 orders of magnitude smaller, and the normalized imidazole mass is $2-3$ orders of magnitude less than the glyoxal oligomer fragments. The normalized C-N compounds and the imidazole products have increased by up to two orders of magnitude compared with pre-reaction background values, exhibiting the same trend of decreasing normalized mass with increasing RH values.

Figure 5 shows the ratios (normalized to sulfate mass) of C-N compounds to glyoxal oligomerization products and the ratio of imidazoles only, to the glyoxal oligomerization products versus $\mathrm{RH}$ values. The $\mathrm{C}-\mathrm{N}$ compounds' ratio are $30 \times 10^{-3}, 38 \times 10^{-3}$, and $46 \times 10^{-3}$ for the reactions 
Table 3. Comparison to literature values of the mass growth rate and the ratio of final mass to seed mass (normalized by sulfate mass) assuming linear reaction rate, from AMS data, after $4 \mathrm{~h}$ of reaction of AS $300 \mathrm{~nm}$ with glyoxal gas.

\begin{tabular}{|c|c|c|c|c|c|c|c|c|}
\hline \multirow[b]{2}{*}{$\begin{array}{l}\text { RH } \\
\text { value }\end{array}$} & \multicolumn{3}{|c|}{ Glyoxal gas concentration (ppb) } & \multicolumn{2}{|c|}{$\begin{array}{l}\text { Mass Growth rate } \\
\left(\mu \mathrm{g}^{-1} \min ^{-1}\right)\end{array}$} & \multicolumn{3}{|c|}{ Final mass/ seed mass after $4 \mathrm{~h}$} \\
\hline & This study & $\begin{array}{l}\text { Liggio et al. } \\
(2005 \mathrm{a})\end{array}$ & $\begin{array}{l}\text { Galloway et al. } \\
\text { (2009) }\end{array}$ & This study & $\begin{array}{l}\text { Liggio et al. } \\
(2005 \mathrm{~b})\end{array}$ & $\begin{array}{l}\text { This study (assuming } \\
\text { linear reaction rate) }\end{array}$ & $\begin{array}{l}\text { Liggio et al. } \\
(2005 \mathrm{a})\end{array}$ & $\begin{array}{l}\text { Galloway et al. } \\
\text { (2009) }\end{array}$ \\
\hline $50 \%^{\mathrm{a}}$ & $\sim 2$ & $\sim 5$ & $\sim 67$ & $8.85 \times 10^{-12} \pm 3.29 \times 10^{-13}$ & $6 \times 10^{-11}$ & $13.30 \pm 0.79$ & 16 & 0.35 \\
\hline $75 \%$ & $\sim 2$ & & & $2.83 \times 10^{-12} \pm 3.68 \times 10^{-13}$ & - & $6.98 \pm 0.50$ & - & - \\
\hline $90 \%$ & $\sim 2$ & & & $1.59 \times 10^{-12} \pm 3.13 \times 10^{-13}$ & - & $5.68 \pm 0.40$ & - & - \\
\hline
\end{tabular}

${ }^{a}$ RH values for Liggio et al. (2005a, b) are $49 \%$ and seed aerosol size of $127.8 \mathrm{~nm}$ and for Galloway et al. (2009) the RH is $55 \%$.

$\mathrm{b}$ Based on the findings of Liggio et al. $(2005 \mathrm{a}, \mathrm{b})$ that the reaction rate is linear in the first $4 \mathrm{~h}$ of their measurements.

conducted at RH values of $50 \%, 75 \%$ and $90 \%$, respectively. The ratio of the imidazoles are $3 \times 10^{-3}, 5 \times 10^{-3}$, $8 \times 10^{-3}$ for the RH values of $50 \%, 75 \%$ and $90 \%$, respectively. There is an increase in the relative contribution of the absorbing $\mathrm{C}-\mathrm{N}$ compounds compared to the glyoxal products with increasing RH values. This suggests that higher water content enhances the imidazole formation pathway shown in Galloway et al. (2009) (Fig. 9 of their paper) and we can assume that in cloud droplets containing AS, where the water content is higher, this reaction will be further enhanced, leading to a higher ratio of absorbing material, and potentially altering the optical properties by an addition of an absorbing component to their RI.

The RI values derived by the core/shell model at $355 \mathrm{~nm}$ are $n=1.68( \pm 0.10)+0.01( \pm 0.02)$ at $50 \% \mathrm{RH}$ and $n=$ $1.65( \pm 0.06)+0.02( \pm 0.01)$ at $75 \% \mathrm{RH}$. (Table 2$)$. This is the first time, to our knowledge, that an estimation of the RI of the reaction products of AS with glyoxal was performed. The observed increase in the ratio of the absorbing substances (C-N compounds, including imidazoles) to the glyoxal oligomers with increasing $\mathrm{RH}$ values is not indicated in a change in the imaginary part from RH $50 \%$ to $75 \%$. A further increase in the ratio of absorbing substances and a resulting increase in the imaginary part of the RI at higher RH values is expected, and may become even more substantial after longer reaction times (possibly in cloud or fog droplets). However, the sensitivity of the CRD system and the small change in absorption (at least on these time scales and this wavelength) does not enable to detect changes in absorption.

A comparison of the results of the AS $300 \mathrm{~nm}$ particles mass growth in our study to the values measured in Galloway et al. (2009) and Liggio et al. (2005a, b) is presented in Table 3. The ratio of final mass to the seed mass (normalized by sulfate mass) is in the same order of magnitude as found by Liggio et al. (2005b). Our value of $13.30 \pm 0.79$ is slightly smaller than their value of 16 , and our calculated mass growth rate is one order of magnitude smaller. Since we found in this study that the observed relative size change due to the reaction is greater with decreasing initial parti-

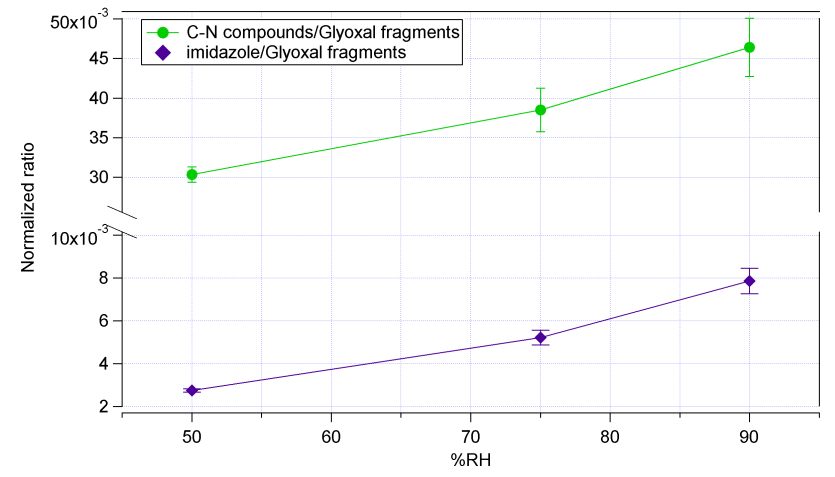

Fig. 5. The ratio of the total C-N compounds to glyoxal fragments (green diamonds) and the imidazoles to glyoxal fragments (purple diamonds) for the reaction of AS $300 \mathrm{~nm}$ particles with glyoxal gas at the measured $\mathrm{RH}$ values is presented. Both ratios show an increase with increasing RH value and decreasing total mass, since the mass of the glyoxal fragments decreases more drastically with increasing $\mathrm{RH}$ than the total $\mathrm{C}-\mathrm{N}$ compounds and imidazoles. All masses are normalized to sulfate mass.

cle size (see Table 1), and our initial seed aerosol size is approximately twice the size used by Liggio et al. (2005b) this difference can be expected. Moreover, the glyoxal gas concentration in our study is $\sim 2 \mathrm{ppb}$ compared to $\sim 5 \mathrm{ppb}$ used by Liggio et al. (2005b) (see Table 3). Both ours and the value of Liggio et al. (2005b) for the ratio of final mass (after four hours) to seed mass are two orders of magnitude larger than that found by Galloway et al. (2009). However, the growth rates cannot be directly compared, since this study and Liggio et al. (2005b) use a monodisperse distribution of aerosols reacting with gas phase glyoxal, and both Galloway et al. (2009) and Kroll et al. (2005) use a polydisperse distribution for the reaction. As shown in this study, the extent of particle growth depends on the initial particle size, therefore not all particles in the population used by Galloway et al. (2009) and Kroll et al. (2005) grow to the same extent, while in this study and in Liggio et al. (2005b) the mass growth per particle can be determined and compared. 
Our experiments were conducted for the hydration process of AS aerosols (i.e. while increasing the RH), followed by drying and consequent efflorescence of the reacted particles. The dehydration process such as in the case of a drying cloud droplet or saturated aerosol particles, involves efflorescence and hysteresis. While the hydration process leads to a deliquescence point for AS particles at approximately $80 \% \mathrm{RH}$, dehydration, their efflorescence point is at $\sim 35 \% \mathrm{RH}$ (Dinar et al., 2007). This suggests that under the same RH conditions (in the $40-80 \%$ range), the reaction of an evaporating AS droplet with the same dry diameter will be slower than for the reaction under hydration conditions, due to the higher water content of the dehydrating particles compared to the hydrating ones.

\section{Atmospheric implications}

The heterogeneous reaction of AS particles with glyoxal under hydrated conditions occurs at a very wide $\mathrm{RH}$ range, from $35 \%$ to $90 \%$ and is therefore relevant under atmospheric conditions varying from arid and semi arid areas to tropical regions. Due to reaction on hydrated AS particles followed by drying and efflorescence, there is formation of secondary organic material composed of glyoxal oligomers and $\mathrm{C}-\mathrm{N}$ containing products that result in particle growth. The enhancement in the optical cross section due to the chemical reactions and the subsequent growth in size affect the potential radiative properties of the reacted particles significantly. This phenomenon is especially important for small aerosols with near-zero extinction efficiency $\left(Q_{\text {ext }}\right)$ values. Following the reaction, the change in size renders them more optically active (up to 2 orders of magnitude enhancement in optical extinction cross section).

The increase in particle size due to the reaction affects the particles' microphysical properties in addition to their radiative properties. Larger particles act as better cloud condensation nuclei (CCN). However, in order to fully establish the microphysical properties of the product aerosols, the hygroscopicity of the glyoxal oligomerization product compounds needs to be studied.

The glyoxal gas concentration used in this study is $\sim 2 \mathrm{ppb}$, in the range of atmospheric glyoxal concentrations, found to be between 0.01-5 ppb (Grosjean et al., 1996; Grossmann et al., 2003; Liggio et al., 2005b; Volkamer et al., 2007; Wittrock et al., 2006), and the experiments were conducted for $1 \mathrm{~h}$. This suggests that the observed changes due to the reaction can occur within $1 \mathrm{~h}$ in the ambient atmosphere. Although Galloway et al. (2009) have shown that the glyoxal oligomerization in the particle phase is reversible, the temporary change in particle size and optical properties due to the reaction can cause a long term effect on both radiative properties and cloud formation in the region it occurs.

This study shows that the heterogeneous reaction of glyoxal and AS aerosols can affect both the SOA mass and the radiative effect of the aerosol. The extent of change depends strongly on the size and the $\mathrm{RH}$, as well as the direction of $\mathrm{RH}$ change of the reacting particles.

Acknowledgements. Funding was provided by the Israel Science Foundation (Grant \#196/08). Y. R. acknowledges support by the Helen and Martin Kimmel Award for Innovative Investigation. We thank Alex Kostinski for his contribution to the data analysis. We thank Soeren Zorn for his assistance with the presentation of the AMS analysis.

Edited by: V. F. McNeill

\section{References}

Abo Riziq, A., Erlick, C., Dinar, E., and Rudich, Y.: Optical properties of absorbing and non-absorbing aerosols retrieved by cavity ring down (CRD) spectroscopy, Atmos. Chem. Phys., 7, 15231536, doi:10.5194/acp-7-1523-2007, 2007.

Abo Riziq, A., Trainic, M., Erlick, C., Segre, E., and Rudich, Y.: Extinction efficiencies of coated absorbing aerosols measured by cavity ring down aerosol spectrometry, Atmos. Chem. Phys., 8, 1823-1833, doi:10.5194/acp-8-1823-2008, 2008.

Carlton, A. G., Turpin, B. J., Altieri, K. E., Seitzinger, S., Reff, A., Lim, H. J., and Ervens, B.: Atmospheric oxalic acid and SOA production from glyoxal: Results of aqueous photooxidation experiments, Atmos. Environ., 41, 7588-7602, 2007.

Cho, J. R., Cho, S. G., Goh, E. M., and Kim, J. K.: Preparation method of 2,2'-B1-1H-imidazole using glyoxal and an ammonium salt, Agency for Defense Development, Daejeon (KR), United States, 2004.

Corrigan, A. L., Hanley, S. W., and Haan, D. O.: Uptake of glyoxal by organic and inorganic aerosol, Environ. Sci. Technol., 42, 4428-4433, 2008.

Cruz, C. N. and Pandis, S. N.: Deliquescence and hygroscopic growth of mixed inorganic-organic atmospheric aerosol, Environ. Sci. Technol., 34, 4313-4319, 2000.

Cziczo, D. J. and Abbatt, J. P. D.: Deliquescence, efflorescence, and supercooling of ammonium sulfate aerosols at low temperature: Implications for cirrus cloud formation and aerosol phase in the atmosphere, J. Geophys. Res.-Atmos., 104, 13781-13790, 1999.

De Haan, D. O., Corrigan, A. L., Tolbert, M. A., Jimenez, J. L., Wood, S. E., and Turley, J. J.: Secondary Organic Aerosol Formation by Self-Reactions of Methylglyoxal and Glyoxal in Evaporating Droplets, Environ. Sci. Technol., 43, 8184-8190, 2009.

Dinar, E., Taraniuk, I., Graber, E. R., Anttila, T., Mentel, T. F., and Rudich, Y.: Hygroscopic growth of atmospheric and model humic-like substances, J. Geophys. Res.-Atmos., 112, D05211, 2007.

Dinar, E., Riziq, A. A., Spindler, C., Erlick, C., Kiss, G., and Rudich, Y.: The complex refractive index of atmospheric and model humic-like substances (HULIS) retrieved by a cavity ring down aerosol spectrometer (CRD-AS), Faraday Discuss., 137, 279-295, 2008.

Ervens, B., Carlton, A. G., Turpin, B. J., Altieri, K. E., Kreidenweis, S. M., and Feingold, G.: Secondary organic aerosol yields from cloud-processing of isoprene oxidation products, Geophys. Res. Lett., 35, L02816, doi:10.1029/2007GL031828, 2008. 
Ervens, B., Turpin, B. J., and Weber, R. J.: Secondary organic aerosol formation in cloud droplets and aqueous particles (aqSOA): a review of laboratory, field and model studies, Atmos. Chem. Phys. Discuss., 11, 22301-22383, doi:10.5194/acpd-1122301-2011, 2011.

Fu, T. M., Jacob, D. J., Wittrock, F., Burrows, J. P., Vrekoussis, M., and Henze, D. K.: Global budgets of atmospheric glyoxal and methylglyoxal, and implications for formation of secondary organic aerosols, J. Geophys. Res.-Atmos., 113, D15303, doi:10.1029/2007JD009505, 2008.

Fu, T. M., Jacob, D. J., and Heald, C. L.: Aqueous-phase reactive uptake of dicarbonyls as a source of organic aerosol over eastern North America, Atmos. Environ., 43, 1814-1822, 2009.

Galloway, M. M., Chhabra, P. S., Chan, A. W. H., Surratt, J. D., Flagan, R. C., Seinfeld, J. H., and Keutsch, F. N.: Glyoxal uptake on ammonium sulphate seed aerosol: reaction products and reversibility of uptake under dark and irradiated conditions, Atmos. Chem. Phys., 9, 3331-3345, doi:10.5194/acp-9-33312009, 2009.

Graber, E. R. and Rudich, Y.: Atmospheric HULIS: How humiclike are they? A comprehensive and critical review, Atmos. Chem. Phys., 6, 729-753, doi:10.5194/acp-6-729-2006, 2006.

Grosjean, E., Grosjean, D., Fraser, M. P., and Cass, G. R.: Air quality model evaluation data for organics .2. C-1-C-14 carbonyls in Los Angeles air, Environ. Sci. Technol., 30, 2687-2703, 1996.

Grossmann, D., Moortgat, G. K., Kibler, M., Schlomski, S., Bachmann, K., Alicke, B., Geyer, A., Platt, U., Hammer, M. U., Vogel, B., Mihelcic, D., Hofzumahaus, A., Holland, F., and Volz-Thomas, A.: Hydrogen peroxide, organic peroxides, carbonyl compounds, and organic acids measured at Pabstthum during BERLIOZ, J. Geophys. Res.-Atmos., 108, 8250, doi:10.1029/2001JD001096, 2003.

Gysel, M., Weingartner, E., and Baltensperger, U.: Hygroscopicity of aerosol particles at low temperatures. 2. Theoretical and experimental hygroscopic properties of laboratory generated aerosols, Environ. Sci. Technol., 36, 63-68, 2002.

Hallquist, M., Wenger, J. C., Baltensperger, U., Rudich, Y., Simpson, D., Claeys, M., Dommen, J., Donahue, N. M., George, C., Goldstein, A. H., Hamilton, J. F., Herrmann, H., Hoffmann, T., Iinuma, Y., Jang, M., Jenkin, M. E., Jimenez, J. L., Kiendler-Scharr, A., Maenhaut, W., McFiggans, G., Mentel, Th. F., Monod, A., Prvt, A. S. H., Seinfeld, J. H., Surratt, J. D., Szmigielski, R., and Wildt, J.: The formation, properties and impact of secondary organic aerosol: current and emerging issues, Atmos. Chem. Phys., 9, 5155-5236, doi:10.5194/acp-95155-2009, 2009.

Harries, C. and Temme, P.: Über monomolekulares und trimolekulares Glyoxal, Berichte der deutschen chemischen Gesellschaft, 40, 165-172, 1907.

Hastings, W. P., Koehler, C. A., Bailey, E. L., and De Haan, D. O.: Secondary organic aerosol formation by glyoxal hydration and oligomer formation: Humidity effects and equilibrium shifts during analysis, Environ. Sci. Technol., 39, 8728-8735, 2005.

Heald, C. L., Henze, D. K., Horowitz, L. W., Feddema, J., Lamarque, J. F., Guenther, A., Hess, P. G., Vitt, F., Seinfeld, J. H., Goldstein, A. H., and Fung, I.: Predicted change in global secondary organic aerosol concentrations in response to future climate, emissions, and land use change, J. Geophys. Res.-Atmos., 113, D05211, doi:10.1029/2007JD009092, 2008.
Hewitt, C. N. and Harrison, R. M.: TROPOSPHERIC CONCENTRATIONS OF THE HYDROXYL RADICAL - A REVIEW, Atmos. Environ., 19, 545-554, 1985.

Huisman, A. J., Hottle, J. R., Galloway, M. M., DiGangi, J. P., Coens, K. L., Choi, W., Faloona, I. C., Gilman, J. B., Kuster, W. C., de Gouw, J., Bouvier-Brown, N. C., Goldstein, A. H., LaFranchi, B. W., Cohen, R. C., Wolfe, G. M., Thornton, J. A., Docherty, K. S., Farmer, D. K., Cubison, M. J., Jimenez, J. L., Mao, J., Brune, W. H., and Keutsch, F. N.: Photochemical modeling of glyoxal at a rural site: observations and analysis from BEARPEX 2007, Atmos. Chem. Phys., 11, 8883-8897, doi:10.5194/acp-11-88832011, 2011.

Jimenez, J. L., Canagaratna, M. R., Donahue, N. M., Prevot, A. S. H., Zhang, Q., Kroll, J. H., DeCarlo, P. F., Allan, J. D., Coe, H., Ng, N. L., Aiken, A. C., Docherty, K. S., Ulbrich, I. M., Grieshop, A. P., Robinson, A. L., Duplissy, J., Smith, J. D., Wilson, K. R., Lanz, V. A., Hueglin, C., Sun, Y. L., Tian, J., Laaksonen, A., Raatikainen, T., Rautiainen, J., Vaattovaara, P., Ehn, M., Kulmala, M., Tomlinson, J. M., Collins, D. R., Cubison, M. J., Dunlea, E. J., Huffman, J. A., Onasch, T. B., Alfarra, M. R., Williams, P. I., Bower, K., Kondo, Y., Schneider, J., Drewnick, F., Borrmann, S., Weimer, S., Demerjian, K., Salcedo, D., Cottrell, L., Griffin, R., Takami, A., Miyoshi, T., Hatakeyama, S., Shimono, A., Sun, J. Y., Zhang, Y. M., Dzepina, K., Kimmel, J. R., Sueper, D., Jayne, J. T., Herndon, S. C., Trimborn, A. M., Williams, L. R., Wood, E. C., Middlebrook, A. M., Kolb, C. E., Baltensperger, U., and Worsnop, D. R.: Evolution of Organic Aerosols in the Atmosphere, Science, 326, 1525-1529, 2009.

Kalberer, M., Paulsen, D., Sax, M., Steinbacher, M., Dommen, J., Prevot, A. S. H., Fisseha, R., Weingartner, E., Frankevich, V., Zenobi, R., and Baltensperger, U.: Identification of polymers as major components of atmospheric organic aerosols, Science, 303, 1659-1662, 2004.

Kanakidou, M., Seinfeld, J. H., Pandis, S. N., Barnes, I., Dentener, F. J., Facchini, M. C., Van Dingenen, R., Ervens, B., Nenes, A., Nielsen, C. J., Swietlicki, E., Putaud, J. P., Balkanski, Y., Fuzzi, S., Horth, J., Moortgat, G. K., Winterhalter, R., Myhre, C. E. L., Tsigaridis, K., Vignati, E., Stephanou, E. G., and Wilson, J.: Organic aerosol and global climate modelling: a review, Atmos. Chem. Phys., 5, 1053-1123, doi:10.5194/acp-5-1053-2005, 2005.

Kroll, J. H. and Seinfeld, J. H.: Chemistry of secondary organic aerosol: Formation and evolution of low-volatility organics in the atmosphere, Atmos. Environ., 42, 3593-3624, 2008.

Kroll, J. H., Ng, N. L., Murphy, S. M., Varutbangkul, V., Flagan, R. C., and Seinfeld, J. H.: Chamber studies of secondary organic aerosol growth by reactive uptake of simple carbonyl compounds, J. Geophys. Res.-Atmos., 110, D23207, doi:10.1029/2005JD006004, 2005.

Lang-Yona, N., Rudich, Y., Segre, E., Dinar, E., and Abo-Riziq A.: Complex Refractive Indices of Aerosols Retrieved by Continuous Wave-Cavity Ring Down Aerosol Spectrometer, Anal. Chem., 81, 1762-1769, 2009.

Liggio, J., Li, S. M., and McLaren, R.: Heterogeneous reactions of glyoxal on particulate matter: Identification of acetals and sulfate esters, Environ. Sci. Technol., 39, 1532-1541, 2005a.

Liggio, J., Li, S. M., and McLaren, R.: Reactive uptake of glyoxal by particulate matter, J. Geophys. Res.-Atmos., 110, D10304, doi:10.1021/es048375y, 2005b. 
Liu, L., Wang, H., Yu, B., Xu, Y., and Shen, J.: Improved algorithm of light scattering by a coated sphere, China Particuology, 5, 230-236, 2007.

Mikhailov, E., Vlasenko, S., Martin, S. T., Koop, T., and Pöschl, U.: Amorphous and crystalline aerosol particles interacting with water vapor: conceptual framework and experimental evidence for restructuring, phase transitions and kinetic limitations, Atmos. Chem. Phys., 9, 9491-9522, doi:10.5194/acp-9-9491-2009, 2009.

Myriokefalitakis, S., Vrekoussis, M., Tsigaridis, K., Wittrock, F., Richter, A., Brühl, C., Volkamer, R., Burrows, J. P., and Kanakidou, M.: The influence of natural and anthropogenic secondary sources on the glyoxal global distribution, Atmos. Chem. Phys., 8, 4965-4981, doi:10.5194/acp-8-4965-2008, 2008.

Noziere, B., Dziedzic, P., and Cordova, A.: Products and Kinetics of the Liquid-Phase Reaction of Glyoxal Catalyzed by Ammonium Ions $\left(\mathrm{NH}_{4}^{+}\right)$, J. Phys. Chem. A, 113, 231-237, 2009.

Noziere, B., Dziedzic, P., and Cordova, A.: Inorganic ammonium salts and carbonate salts are efficient catalysts for aldol condensation in atmospheric aerosols, Phys. Chem. Chem. Phys., 12, 3864-3872, 2010.

Pettersson, A., Lovejoy, E. R., Brock, C. A., Brown, S. S., and Ravishankara, A. R.: Measurement of aerosol optical extinction at $532 \mathrm{~nm}$ with pulsed cavity ring down spectroscopy, J. Aerosol Sci., 35, 995-1011, 2004.

Rudich, Y.: Laboratory perspectives on the chemical transformations of organic matter in atmospheric particles, Chem. Rev., 103, 5097-5124, 2003.

Rudich, Y., Donahue, N. M., and Mentel, T. F.: Aging of organic aerosol: Bridging the gap between laboratory and field studies, Annu. Rev. Phys. Chem., 58, 321-352, 2007.

Schulze, H.: Imidazole Synthesis, edited, Jefferson Chemical Company, Inc., Houston, Texas, United States, 1973.

Schweitzer, F., Magi, L., Mirabel, P., and George, C.: Uptake rate measurements of methanesulfonic acid and glyoxal by aqueous droplets, J. Phys. Chem. A, 102, 593-600, 1998.

Schwier, A. N., Sareen, N., Mitroo, D., Shapiro, E. L., and McNeill, V. F.: Glyoxal-Methylglyoxal Cross-Reactions in Secondary Organic Aerosol Formation, Environ. Sci. Technol., 44, 6174-6182, 2010.

Shapiro, E. L., Szprengiel, J., Sareen, N., Jen, C. N., Giordano, M. R., and McNeill, V. F.: Light-absorbing secondary organic material formed by glyoxal in aqueous aerosol mimics, Atmos. Chem. Phys., 9, 2289-2300, doi:10.5194/acp-9-2289-2009, 2009.
Sinreich, R., Volkamer, R., Filsinger, F., Frieß, U., Kern, C., Platt, U., Sebastin, O., and Wagner, T.: MAX-DOAS detection of glyoxal during ICARTT 2004, Atmos. Chem. Phys., 7, 1293-1303, doi:10.5194/acp-7-1293-2007, 2007.

Sjostedt, S. J., Huey, L. G., Tanner, D. J., Peischl, J., Chen, G., Dibb, J. E., Lefer, B., Hutterli,M. A., Beyersdorf, A. J., Blake, N. J., Blake, D. R., Sueper, D., Ryerson, T., Burkhart, J., and Stohl, A.: Observations of hydroxyl and the sum of peroxy radicals at Summit, Greenland during summer 2003, Atmos. Environ., 41, 5122-5137, 2007.

Tan, Y., Perri, M. J., Seitzinger, S. P., and Turpin, B. J.: Effects of Precursor Concentration and Acidic Sulfate in Aqueous Glyoxal$\mathrm{OH}$ Radical Oxidation and Implications for Secondary Organic Aerosol, Environ. Sci. Technol., 43, 8105-8112, 2009.

Volkamer, R., Spietz, P., Burrows, J., and Platt, U.: High-resolution absorption cross-section of glyoxal in the UV-vis and IR spectral ranges, J. Photochem. Photobiol. A, 172, 35-46, 2005.

Volkamer, R., Martini, F. S., Molina, L. T., Salcedo, D., Jimenez, J. L., and Molina, M. J.: A missing sink for gas-phase glyoxal in Mexico City: Formation of secondary organic aerosol, Geophys. Res. Lett., 34, L19807, doi:10.1029/2007GL030752, 2007.

Volkamer, R., Ziemann, P. J., and Molina, M. J.: Secondary Organic Aerosol Formation from Acetylene $\left(\mathrm{C}_{2} \mathrm{H}_{2}\right)$ : seed effect on SOA yields due to organic photochemistry in the aerosol aqueous phase, Atmos. Chem. Phys., 9, 1907-1928, doi:10.5194/acp9-1907-2009, 2009.

Wittrock, F., Richter, A., Oetjen, H., Burrows, J. P., Kanakidou, M., Myriokefalitakis, S., Volkamer, R., Beirle, S., Platt, U., and Wagner, T.: Simultaneous global observations of glyoxal and formaldehyde from space, Geophys. Res. Lett., 33, L16804, doi:10.1029/2006GL026310, 2006.

Zhang, Q., Jimenez, J. L., Canagaratna, M. R., Allan, J. D., Coe, H., Ulbrich, I., Alfarra, M.R., Takami, A., Middlebrook, A M., Sun, Y. L., Dzepina, K., Dunlea, E., Docherty, K., DeCarlo, P. F., Salcedo, D., Onasch, T., Jayne, J. T., Miyoshi, T., Shimono, A., Hatakeyama, S.,Takegawa, N., Kondo, Y., Schneider, J., Drewnick, F., Borrmann, S., Weimer, S., Demerjian,K., Williams, P., Bower, K., Bahreini, R., Cottrell, L., Griffin, R. J., Rautiainen, J., Sun, J. Y.,Zhang, Y. M., and Worsnop, D. R.: Ubiquity and dominance of oxygenated species in organic aerosols in anthropogenically-influenced Northern Hemisphere midlatitudes, Geophys. Res. Lett., 34, L13801, doi:10.1029/2007GL029979, 2007. 